\title{
A TEORIA HISTÓRICO-CULTURAL E A DIALÉTICA INCLUSÃO/EXCLUSÃO NAS INSTITUIÇÕES DE ENSINO
}

\author{
THE HISTORICAL CULTURAL THEORY AND DIALECTIC \\ INCLUSION/EXCLUSION IN EDUCATION INSTITUTIONS
}

LA THÉORIE HISTORICO-CULTURELLE ET LA DIALECTIQUE INCLUSION/EXCLUSION DANS LES INSTITUITIONS D’ENSEIGNEMENT

LA TEORÍA HISTÓRICO-CULTURAL Y LA DIALÉTICA INCLUSIÓN/EXCLUSIÓN EN LAS INSTITUCIONES DE ENSEÑANZA

Candice Marques de Lima*

Mercedes Villa Cupolillo **

\section{RESUMO}

O presente artigo tem como objetivo discutir o processo de inclusãolexclusão escolar a partir da perspectiva histórico-cultural. Nessa perspectiva discutimos a inclusão como um processo dialético que acontece nos indivíduos envolvidos nos contextos educacionais, por meio de relaçôes intersubjetivas. Complexo e contraditório, o processo de inclusão não está limitado à visão da deficiência, mas estende-se a todos os membros dos grupos a que o indivíduo pertence, promovendo práticas pedagógicas e sociais para atender a diversidade humana. Nessa proposta, a comunicação dialógica entre professor e aluno é o ponto fundamental para que este se constitua como sujeito no seu processo de conhecimento, sentindo-se incluido nas relaçoes sociais e humanas.

Palavras-chave: Teoria histórico-cultural. Inclusão. Diversidade. Comunicação.

* Graduada em Psicologia e Mestra em Psicologia do Desenvolvimento pela Universidade Católica de Goiás. Professora na Faculdade Araguaia, Goiânia - GO (candicemarques1@gmail.com).

** Graduada em Psicologia e Doutora em Psicologia do Desenvolvimento pela Universidade de Dundee (Escócia, 1993). Psicóloga e pesquisadora do Instituto Heloisa Marinho, Niterói - RJ. Professora da Faculdade Paraíso (RJ) e Universidade da Zona Oeste (RJ) (mercedescupolillo@hotmail.com). 


\section{INTRODUÇÃO}

Não se pode reformar a instituição sem a prévia reforma das mentes, mas não se podem reformar as mentes sem uma prévia reforma das instituiçôes (MORIN, 2000, p. 99).

A história do século XX - uma era de extremos, conforme afirma o historiador Hobsbawm (1995) - foi palco de diversos avanços, e também retrocessos, responsáveis por mudanças tecnológicas e sociais nunca acontecidas de maneira tão rápida na história da humanidade. $\mathrm{O}$ mundo passou por duas grandes guerras, por revoluçóes socialistas que se iniciaram e algumas terminaram no mesmo século, pelo extermínio em massa de grupos étnicos que ameaçavam os interesses econômicos e sociais do país onde viviam; e também por avanços científicos e tecnológicos: os antibióticos, que combateram doenças que antes eram consideradas mortais, e o surgimento e avanço de sistemas de comunicação como a televisão, o telefone e a internet, para citar apenas alguns dos mais importantes. Com isso uma nova era se funda - a era globalizada, um mundo sem fronteiras, no qual as informaçôes e o contato com pessoas acontecem em tempo real independentemente da distância em que os acontecimentos ou as pessoas possam estar.

Neste contexto, em que culturas e pessoas distantes ou desconhecidas podem ser acessadas e descobertas por um click na tecla do computador, faz-se necessária uma visão de mundo na qual não existam fronteiras apenas entre as nações e os povos, mas também entre as pessoas próximas, principalmente as estigmatizadas e excluídas por marcas físicas e/ou sociais.

Surge, dessa forma, um movimento que se desenvolve em uma subjetividade social, marcado pela ação de sujeitos que, ao promover discussões, apontar críticas e apresentar soluções, cria zonas de tensão na sociedade, que se mobiliza para compreender a inclusão de pessoas com necessidades especiais nos diversos espaços sociais.

A proposta de inclusão de pessoas portadoras de deficiências sensoriais, físicas e mentais ou de impedimentos construídos socialmente, que servem para explicar a incapacidade que certos grupos ou indivíduos têm de ascensão intelectual e/ou social nos diversos espaços sociais, não surgiu de repente. Como procuramos mostrar brevemente, na história do século XX, o ideal de inclusão é um processo complexo que se iniciou e constituiu com o desenvolvimento da ciência, desde o período do iluminismo, com o desenvolvimento das tecnologias, com o fim da escravidão, com a conquista das mulheres por seus direitos à educação e ao trabalho e também pela aversão à repetição de holocaustos ocorridos ao longo da história da humanidade, especialmente o holocausto dos judeus no século XX, ainda recente em nossa história; além de outros fatores, que também influenciaram esse processo que tem se desenvolvido desde as décadas de $60 \mathrm{e}$ 70, mas que ganhou o nome de inclusão nos anos 90 .

A inclusão não é um processo já pronto e acabado nas sociedades, e, sim, uma proposta que tem permeado a subjetividade social, se desenvolvendo e também encontrando resistências de diversas formas e por vários setores da sociedade e pessoas. Como afirma Barboza (2001), a inclusão é um fenômeno complexo, multideterminado e multifacetado. Por isso mobiliza e provoca interesse e resistência, nos chama para olhar 
o outro com suas faltas e dificuldades e nos lembra a nossa própria mortalidade e imperfeiçōes.

A discussão a respeito da inclusão da diferença/diversidade também se apresenta como uma contradição ao nosso modo capitalista de ser/ter/pensar, já que, para sermos "felizes", uma felicidade fugaz, alicerçada na imagem efêmera do que é considerado belo e na obtenção da mercadoria, precisamos ser altamente produtivos e para isso temos de ser iguais e ao mesmo tempo originais - a grande contradição da tão controversa pósmodernidade. Os estereótipos de uma beleza européia ou americanizada, isto é, ser branco, ter olhos e cabelos claros, corpo atlético, que sirva para suportar as agruras do dia-a-dia, e capacidade intelectual acima da média, estão impregnados em nossa concepção do que é preciso ser para ter e vice-versa. As roupas também vêm em kits prontos para serem consumidos, basta escolher em qual grupo a pessoa quer se enquadrar e para isso é necessário apenas ir a uma loja que trabalhe com determinado tipo de roupa para sair de lá com um estilo "só seu". O que antes era considerado rebeldia - um jeans surrado, uma camiseta com fotografia de Che Guevara e cabelos compridos e desgrenhados - já se pode encontrar em qualquer loja que se preze. Tudo vira mercadoria a módicos preços, acessíveis a quem tem "bom gosto e estilo próprio".

$\mathrm{Na}$ contramão dessa estética contemporânea estão as pessoas com deficiência, os negros, os pobres, os índios, os obesos, enfim, as minorias/maiorias que têm de se enquadrar como podem nesses modelos para conseguir "um lugar ao sol". Olhamos para essas pessoas com compaixão e procuramos de alguma forma ajudá-las, nos posicionamos em favor desse movimento inclusivo que vem se constituindo em nossa sociedade e queremos realmente que a inclusão social aconteça, que todos os espaços sejam espaços de todos. Mas como fazer isso? Essa é uma pergunta sobre a qual pensamos diversas vezes e que tentamos, se não responder, pelo menos lançar um olhar para que a discussão se desenvolva.

\section{O PROCESSO DE BUSCA DO CONHECIMENTO CIENTÍFICO E A CONSTITUIÇÃO DA PSICOLOGIA COMO CIÊNCIA NO BRASIL}

Com o fim da Idade Média e sua forma de produção feudal, na qual as relações se dão em valores de uso e o princípio que organiza a vida é a religião, surge uma nova organização econômica, social e cultural - o capitalismo. Funda-se aí a modernidade, na qual as relações se dão em valores de troca e o princípio que organiza o Estado é o de que todos os homens são iguais perante a lei, diferentemente do modo feudal, no qual todos os homens são iguais por serem filhos de Deus. Uma nova forma de constituição das subjetividades social e individual se desenvolve com o surgimento do sistema capitalista, no qual aparece um novo conceito de homem e de trabalho que muda a forma de pensar e agir da humanidade. Um novo homem é forjado baseado em teorias científicas que rejeitam as idéias religiosas como explicação para todos os fenômenos, e o conhecimento científico torna-se a explicação para tais fenômenos. Surgem, portanto, uma nova ética baseada no trabalho e a ascensão de uma classe, a burguesia, provocando a queda, ainda que não abrupta e definitiva, das monarquias, nobreza e religiosos (HOBSBAWM, 1982). 
Nessa subjetividade social, permeada por um desenvolvimento científico e tecnológico, a escola torna-se uma instituição universal, obrigatória e leiga, que se constitui em política educacional no século XIX, embasada de um lado na "crença no poder da razão e da ciência, legado do iluminismo; de outro, o projeto liberal de um mundo onde a igualdade de oportunidades viesse a substituir a invejável desigualdade baseada na herança familiar" (PATTO, 1996, p. 22).

Com as modificações sociais que ocorreram com o desenvolvimento do capitalismo, as pessoas começaram a acreditar que seria possível um modelo de vida baseado na igualdade de direitos e deveres para todos os cidadãos, e um dos mecanismos sociais capazes de transformar as pessoas de súditos em cidadãos - tornando-as aptas para exercer sua função social e se desenvolver no trabalho e ascender economicamente - seria a escola. Enquanto isso, na contramão desse movimento de busca da educação para a melhoria tecnológica e de qualidade de vida estavam as pessoas com deficiência, que eram vistas como incapazes para o aprendizado e inaptas para o trabalho e para a vida social.

Nesse processo de busca por um conhecimento científico, desenvolve-se a história da psicologia e sua constituição como ciência, baseada em critérios médicos e pedagógicos, obedecendo às classes dominantes e criando mecanismos de controle, higienização, diferenciação e categorização da sociedade (ANTUNES, 1999; BOCK 2003; PATTO, 1996, 2003). Tanto nas escolas quanto nos hospitais psiquiátricos, a psicologia procurou responder a uma demanda das elites que desejavam a ordem e a normalização, desenvolvendo teorias que justificassem as práticas higienistas, autoritárias e disciplinares nessas instituiçôes. O critério de pessoa normal passou a ser o de quem trabalhava e obedecia, quem não protestava e colaborava para a ordem estabelecida, fora isso, estava o comportamento patológico. Imaginemos, pois, em um país considerado subdesenvolvido como o Brasil, no qual não há emprego para todos e a desigualdade social é gritante, quais pessoas são consideradas normais e em quais classes sociais prolifera o critério de anormalidade.

Nas escolas, que são o foco de nosso estudo, a ciência psicológica falava de uma moral como inerente ao homem, que se degenera quando a perde, naturalizando, assim, características humanas que também se constituem sócio-historicamente. Buscava-se o controle dos impulsos que eram considerados inadequados nas crianças por meio de práticas disciplinares e moralistas.

A chegada do século XX trouxe à psicologia o estatuto de ciência autônoma na Europa e posteriormente nos Estados Unidos. A educação nessa época estava embasada pelo movimento escolanovista, que "colocou o indivíduo como eixo de sua construção e deu ênfase à preocupação cientificista, transformando as escolas em verdadeiros laboratórios" (BOCK, 2003, p. 18). Esse movimento passou a valorizar a infância e aboliu castigos e vigilância disciplinar nas escolas, colocando em seu lugar a vigilância psicológica. Dessa forma, a psicologia contribuiu, com algumas de suas teorias do desenvolvimento humano, para endossar os trabalhos pedagógicos.

O modelo taylorista, de produção de carros e outras "coisas" em grande escala, também foi endossado pela psicologia nas instituições escolares, no qual se privilegiava eficiência, rapidez e produção em série de alunos acríticos, produzindo sua padronização e homogeneidade, que segundo Patto (2003, p. 33) é onde se desenvolve "a via da 
naturalização da desigualdade que tem origem na maneira como a sociedade se estrutura, mas é lida como diferença biológica ou psicológica de aptidão intelectual entre grupos e indivíduos". Assim, as desigualdades sociais tornam-se desigualdades étnicas, pessoais ou culturais, corroboradas por filósofos e cientistas.

Outra forma de padronizar, estigmatizar e também excluir crianças do contexto escolar são os testes psicológicos, em especial os de inteligência, que se inserem como uma forma objetiva e científica de conhecimento dos mais aptos e dos menos aptos para a educação, mas na verdade as respostas dadas pelo sujeito durante o teste são baseadas em critérios apriorísticos que não levam em consideração a realidade sociocultural do sujeito pesquisado nos testes e muito menos seu aspecto subjetivo. Esse tipo de diagnóstico despersonalizado e descontextualizado "produz o que se diagnostica", nas palavras de González Rey (2002, p. 104). O autor apresenta essa idéia e a exemplifica com a situação de uma criança vítima de fracasso escolar que, quando é encaminhada a um psicólogo, passa por uma bateria de testes de forma despersonalizada e que reproduz na criança o sentido subjetivo de fracasso que esta vivenciou. Assim, o teste tem um importante efeito sobre sua segurança e auto-estima, o que leva a um resultado já esperado pela família, escola e criança, que fracassou por ser incapaz de aprender e ter um baixo escore de inteligência. Desse modo, toda a responsabilidade do fracasso escolar é depositada na criança e tira a responsabilidade da família, da escola e de outros espaços de subjetividade social nos quais a criança se desenvolve e se constitui subjetivamente.

Os testes, portanto, foram e ainda continuam a ser, quando aplicados de forma descontextualizada, poderosos instrumentos científicos construídos pela ciência psicológica para que os mais capazes, ou seja, as crianças com melhores percentuais de inteligência, ocupem os melhores lugares sociais, sem que se observe que essas crianças são, em sua maioria, provenientes de classes sociais privilegiadas, bem alimentadas, limpas e freqüentadoras das melhores escolas, e que seus resultados servem de padrão para se analisar todas as crianças, independentemente de suas classes sociais, necessidades vitais e moradias.

Todas essas idéias, teorias e seus instrumentos científicos serviram por um lado para criar padrōes de normalidade na escola e separar as crianças de acordo com suas capacidades de inteligência. Patto (1996) esclarece que, quando o conceito de problemas de aprendizagem começou a se desenvolver, foram criados "pavilhões especiais para os 'duros de cabeça' ou idiotas, anteriormente confundidos com os loucos" (PATTO, 1996, p. 41). Dessa forma, ocorreu a passagem do conceito de anormalidade dos hospitais para a escola, e as crianças com dificuldades de aprendizagem foram "designadas como anormais escolares e as causas de seu fracasso são procuradas em alguma anormalidade orgânica" (PATTO, 1996, p. 41) (grifo da autora).

As escolas especiais destinadas às crianças com deficiência foram, e ainda são, outro modelo de rotulação e segregação sociais, pois lá eram inseridas as crianças não aceitas no sistema regular de ensino. Ferreira e Guimarães (2003) esclarecem que, embora o século XX tenha trazido a noção de cidadania para as pessoas com deficiência, estas ainda eram atendidas de maneira assistencial e caritativa, sob a hegemonia médica. Surgem, então, movimentos organizados por pais de crianças com deficiência, como a Associação de Pais e Amigos dos Excepcionais (APAE), que dividem o sistema educacional em dois 
subsistemas: a educação regular e a especial. Essas instituições tiveram seu pleno desenvolvimento na década de 1960 com as escolas especiais, centros de reabilitação e associações desportivas especiais, já que, como a sociedade negava espaços para essas pessoas, era necessário criá-los onde fossem oferecidos serviços para essa população.

Outra forma de segregação, em nossa concepção, eram as instituições que no início do século XX ainda não eram consideradas educacionais, mas de guarda de crianças: as creches. Seu desenvolvimento histórico está relacionado com a entrada das mulheres em grande escala no mercado de trabalho. Elas necessitavam de espaços onde pudessem deixar seus filhos pequenos.

No Brasil, as creches, asilos e jardins-de-infância eram dirigidos à população pobre como uma nova concepção assistencial (SOUSA, 2000). As primeiras creches instaladas em São Paulo na década de 1920 atendiam principalmente crianças órfãs e carentes em regime de internato, tendo funções de guarda das crianças, restritas a atividades de assistência médica e sanitária. Sua subordinação a órgãos de assistência social e à clientela à qual atendia fez com que o trabalho das creches fosse voltado para a guarda e nutrição das crianças, esquecendo-se seu desenvolvimento cognitivo-afetivo. Isto se explica devido às concepçōes higienistas e curativas já discutidas acima que também eram aplicadas aos pobres e aos negros em nossa sociedade. A essas pessoas que faziam parte de um exército de proletários ao qual não cabia pensar, apenas executar tarefas braçais, a creche se destinava como instituição para cuidar de seus filhos, que só necessitavam de cuidados físicos e alimentação. Dessa forma, estava instalado um modelo segregacional aos filhos das populações carentes, enquanto as crianças pequenas de classe média e alta eram educadas em pré-escolas onde se discutia a necessidade da promoção de seu desenvolvimento intelectual.

Atualmente, as creches fazem parte do sistema educacional e com isso tornam-se instituições educacionais nas quais deve ser priorizado o desenvolvimento integral da criança, considerando seus conhecimentos de mundo, de si e do outro, por meio da interação com seus colegas e pessoas capacitadas para isso. A criança deve ser compreendida como sujeito que se constitui em um determinado meio socioeconômico e cultural. Infelizmente, ainda observamos na creche, por meio de nossa pesquisa (LIMA, 2004), como essas interações educadora-criança se desenvolvem e que muitas ainda são excluídas por serem provenientes de determinadas famílias em certos contextos sociais.

Ainda nessa era de extremos que foi o breve século XX, as décadas de 1960 e 1970 foram palco de grandes revoluções sociais em busca de uma sociedade mais justa, que aceitasse as diferenças. Nesse contexto proliferaram muitos movimentos: os hippies pregavam paz e amor em oposição à guerra do Vietnã; mulheres queimaram sutiãs em praça pública como protesto e defesa de seu crescimento na sociedade; jovens com ideais socialistas foram torturados e mortos nos porões da ditadura militar brasileira. Enfim, esses e muitos outros movimentos protestavam por ideais diferentes do que já estava estabelecido na sociedade. Na psiquiatria surgiu um movimento denominado antipsiquiatria, que questionava a loucura como uma doença mental, afirmando que na verdade era produzida socialmente. Propunha esse movimento o fim dos manicômios e a inclusão de seus internos na sociedade. 
A sociedade caminhava, portanto, para um movimento social que inserisse os que estavam à sua margem. A Organização das Nações Unidas (ONU) instituiu o ano de 1981 como o Ano Internacional das Pessoas Deficientes, voltando o olhar de diversos setores da sociedade para os que antes eram excluídos e segregados (FUNDAÇÃO BANCO DO BRASIL, 2003). Esse e outros movimentos, além de declarações como as de Cuenca (1981) ${ }^{1}$ e Salamanca (1994), ${ }^{2}$ promoveram discussões e debates em favor da inclusão.

O surgimento do processo de inclusão escolar propiciou diversos estudos e discussões que permeiam as práticas educativas/pedagógicas em nossa sociedade. Apesar disso, existem práticas educacionais que se denominam inclusivas, mas que ainda são, em sua concepção teórica e em seu projeto político-pedagógico, segregadoras. Veja-se a diferenciação que Mantoan (2000) faz entre inclusão e integração, sendo que a última é uma prática que ainda se mantém em nossa sociedade e muitas vezes é denominada inclusão.

Mantoan (2000) esclarece que integração e inclusão expressam situações de inserção diferentes e divergentes em suas metas. Um dos tipos de integração escolar é denominado de mainstreaming, ou seja, corrente principal, pois em seu fluxo é carregado todo tipo de aluno com ou sem capacidade específica, e sua formação será adaptada de acordo com suas necessidades específicas, se baseando na individualização dos programas instrucionais. Nesse processo de integração em que sua estrutura é denominada sistema de cascata, o aluno passaria por todas as etapas da integração - da classe especial à classe regular. Mas o que realmente acontece é que a maioria dos alunos que participam dos serviços segregados não se desloca para as classes regulares, pois, segundo a autora, nesse sistema a escola oculta o próprio fracasso, isola os alunos e integra apenas os que não são um desafio à sua competência.

$\mathrm{O}$ que se pode perceber nesse tipo de integração e em outros tipos, como as classes de aceleração, é que o "problema", seja uma deficiência de qualquer ordem ou a tão propalada dificuldade de aprendizagem - que acomete principalmente os alunos das classes sociais menos favorecidas levando-os à repetência -, está sempre no aluno, que precisa de uma força "de caráter", para romper com seu "problema" e vencer suas "limitações". Nessa concepção, como em tantas outras concepções individualistas e naturalizantes, a escola e as pessoas envolvidas nesse processo - professores e família - são meros coadjuvantes que podem ajudar esse aluno, mas a força principal tem de vir dele.

Algumas questôes que norteiam as concepções de integração e inclusão mostram as diferenças existentes entre elas. $\mathrm{O}$ modelo de integração propõe mudanças que privilegiem as pessoas com deficiência, já que acredita que elas ganham mais com a convivência com o outro; as pessoas com deficiência devem se adaptar à sociedade, que apenas se ajusta para integrá-las. Além disso, tenta disfarçar as limitações dessas pessoas para aumentar suas chances, tratando-as em blocos homogêneos. A proposta de inclusão busca inserir todas as crianças na escola regular de forma total e incondicional, e suas mudanças procuram beneficiar a todos e não apenas um grupo específico de pessoas. Com isso, a sociedade deve se adaptar às necessidades do outro e seus sistemas se tornarem de qualidade a todos, trazendo para a discussão que todas as pessoas são diferentes (FUNDAÇÃO BANCO DO BRASIL, 2003), o que põe em relevo a existência de diferentes constituiçôes subjetivas. 


\section{CONTRIBUIÇÕES DA PSICOLOGIA HISTÓRICO-CULTURAL À EDUCAÇÃO INCLUSIVA}

Em seu tratado de defectologia escrito na década de 1920, Vygotsky (1993) pode ser considerado precursor do movimento inclusivo, pois já defendia a inclusão da criança com deficiência na escola comum. Segundo ele, a criança cega deveria começar a freqüentar a escola ao mesmo tempo que as outras crianças e aprender a cuidar de si mesma, além de brincar junto com as crianças que enxergavam.

Ao discutir sobre a constituição subjetiva de crianças com deficiências físicas, sensoriais e mentais em interação com o outro na família e na escola, o psicólogo russo acrescenta que "a condição de incapacidade é apenas um conceito social; uma condição de deficiência é uma extensão anormal da cegueira, surdez ou mudez. A cegueira por ela mesma não torna uma criança incapacitada" (VYGOTSKY, 1993, p. 83-84). ${ }^{3}$ Assim, a noção de incapacidade é produzida socialmente e a deficiência de uma pessoa passa a ser vista como doença, tanto para os que com ela convivem quanto para a própria pessoa, pois a visão social da deficiência é subjetivada pela pessoa com deficiência como deficiência psicológica a partir da exigência social. Mas Vygotsky frisa que a deficiência não torna ninguém incapaz de fazer as coisas e principalmente de se desenvolver.

Nesses estudos, Vygotsky (1993) discute a idéia de compensação, diferentemente do que o senso comum e outras explicações científicas dão a esse conceito. Para ele há uma lenda sobre a compensação biológica, pois nessa concepção a natureza se encarregaria de, ao privar um homem de um órgão sensorial, dar-lhe a recompensa de ter uma melhor capacidade em outro órgão. Deste modo, por exemplo, a criança cega passa a ouvir melhor porque seu ouvido se desenvolveu para substituir a função dos olhos. O que ocorre num caso como esse é uma compensação social, já que o desenvolvimento da criança seria mediado pelo meio social para ser subjetivado como capacidade para uma melhor percepção auditiva.

Ao discutir a produção de sentido de uma menina cega chamada Bruna, Cupolillo 2003 , p. 2) conta como essa criança utilizava a atenção no diálogo com o outro:

Eu não sabia definir se ela usava a atenção dirigida à fala de todos nós para reorganizar seu discurso, ou se utilizava de acordo com seu próprio tempo. Era verdade que seu tempo não correspondia ao meu. Fazia pausas entre a fala de uma pessoa e a sua própria, mais intensas do que eu esperaria em uma conversa informal com crianças de sua idade. Algumas vezes mordia os lábios como se estivesse pensando alto ou fazendo uso de uma fala egocêntrica.

Baseada nesse caso, Cupolillo nos fala sobre a compensação segundo Vygotsky e esclarece que, como não há uma separação entre as dimensões biológicas e sociais no ser humano, "as perdas corporais geram uma reorganização na comunicação que se estabelece entre as pessoas" (CUPOLILLO, 2003, p. 3). Bruna, para interagir com o outro, precisa se desenvolver qualitativamente diferente, e assim pode-se perceber que os mecanismos compensatórios que utiliza são sociais e não automáticos, por não serem somente orgânicos. É o mundo social que medeia a relação do homem com o mundo físico, e o desenvolvimento da criança com deficiência acontece pela situação social de desenvolvimento permeada pela emocionalidade. 
Apesar das propostas inclusivas amplamente discutidas em nossa sociedade, as instituições educacionais ainda se constituem e se desenvolvem para atender crianças que pertencem a um padrão de normalidade proveniente das classes média e alta. As crianças devem se adequar a esse padrão e estar sempre limpas, bem vestidas e ser educadas, mesmo aquelas que vêm de culturas diferentes e/ou que moram em favelas, invasōes e nas periferias das cidades. Esse é o modelo de bom aluno, com o qual as professoras sonham, mesmo aquelas professoras provenientes de classes sociais menos favorecidas. Com essa representação, muitas professoras vão trabalhar em escolas e creches de periferia e, no momento em que entram em contato com outra realidade, diversa da sua ou até mesmo igual à sua, ao invés de perceberem a diversidade humana e suas variadas formas de desenvolvimento, procuram impor um padrão de "normalidade", proveniente das classes sociais dominantes, e endossados pelas ciências psi, às crianças que pretendem educar.

A esse respeito, Barboza (2001) desenvolve um estudo significativo partindo da subjetividade de uma professora de escola pública que trabalha com uma classe inclusiva. A autora apresenta a história da professora Helena, que se sente desvalorizada em sua profissão e pouco amparada em sua prática educacional, pois, embora tenha feito vários cursos para trabalhar com crianças com deficiência, não compreende como as crianças se desenvolvem e se constituem subjetivamente. Além disso, sente-se excluída em suas relaçōes profissionais com os colegas na tomada de decisões quanto à sua profissão e se mostra resistente à inclusão de crianças com necessidades especiais na escola, não se sentindo, portanto, sujeito transformador de sua realidade social. Dessa forma, suas relaçôes com seus alunos em sala de aula são destituídas de diálogo e Helena é significada como uma professora brava pelas crianças, já que é exigente e autoritária nas interações com seus alunos.

Esse trabalho ilustra como a proposta de educação que as professoras deveriam seguir - partindo do conhecimento e da realidade social nos quais o aluno se constitui inverte-se e a proposta torna-se a criança se inserir num processo de ensino-aprendizagem da realidade social dominante, no qual a professora é seu agente de propagação. A interação que se estabelece entre professora e criança já vem marcada por todos " $a$ priori's" da professora, nos quais o conhecimento e a emocionalidade ${ }^{4}$ da criança não são levados em consideração. Destituída de um caráter dialógico permeado pela afetividade, a relação estabelecida muitas vezes não consegue gerar na criança a necessidade para a aprendizagem dos conteúdos desenvolvidos na sala de aula.

A relação professor-aluno se desenvolve no espaço das emoções, e as dificuldades podem acontecer nas interações que acabam por produzir no aluno a dificuldade em aprender e no professor a dificuldade de como ensinar esse aluno que supostamente não aprende. Assim, a rejeição e a indiferença passam a constituir essa relação na qual sentimentos como impotência e incapacidade se produzem nos dois lados e prejudicam a comunicação entre professor e aluno.

A falta de diálogo na escola se estende também às famílias das crianças, que não podem expressar suas opiniōes sobre o desenvolvimento de seus filhos nem contribuir para a proposta de educação escolar, já que a escola não cria uma posição dialógica com a família do aluno, por entender que suas opiniōes são destituídas de caráter científico e 
que têm uma emocionalidade envolvida, objeto este que não deve interferir em uma avaliação do aluno, pois ainda prevalece o caráter positivista de neutralidade.

A escola se apresenta como se estivesse envolvida em uma redoma de vidro, protegida da sociedade na qual está inserida, se configurando socialmente como não constituinte e não constituída pela subjetividade social, fábrica de crianças "puras" que serão no futuro "despejadas" no meio social e que, se a educação que receberam na escola for realmente boa, tornar-se-ão indivíduos éticos e trabalhadores para a ordem e o progresso da nação (AGUIAR; BOCK, 2003).

Por isso, a violência na escola causa comoção social quando, por exemplo, um aluno, em um ato extremo de violência e agressividade, mata um professor ou um colega, pois a visão que a sociedade tem é que a escola é quase um terreno religioso, que deveria ser isento das "impurezas" produzidas na sociedade, que parecem não lhe dizer respeito. A agressividade manifesta pelo aluno dentro da escola é sempre vista como sendo trazida de fora desta, sem se perceber a atmosfera de emocionalidade que permeia suas interações.

Ao compreender as interações humanas dessa forma, podemos perceber como muitas vezes o professor trata o aluno com uma agressividade ou ironia que estão embutidas em observações ou gestos aparentemente "neutros" - destituídos de afetividade. Utilizamos o verbo sentir porque essas interações não acontecem apenas na esfera consciente, mas também como produçôes de sentido que se apresentam como processos inconscientes, nos quais muitas vezes a criança não consegue articular o pensamento com a fala para expor a agressão velada que se estabelece na relação professor-aluno.

Outro momento destituído de comunicação entre o professor e a criança são as avaliações escolares, em que não são levadas em consideração as novas construções que a criança desenvolveu e muito menos o aspecto afetivo envolvido nessas construções. O caráter avaliativo nas instituições de ensino é destituído de uma compreensão da complexidade do sujeito, que não se constitui subjetivamente apenas na escola e, portanto, muitas vezes, o desenvolvimento da criança não é percebido pelo professor, desenvolvimento este que acontece em outras esferas sociais além da esfera escolar.

A avaliação que reifica o resultado em certo ou errado, segundo Esteban (2001), é que determina o sucesso ou o fracasso do aluno. Ela se fundamenta em uma concepção de homogeneidade que tem embutida uma dinâmica de inclusão do aluno bem-sucedido - o que acerta - e exclusão do aluno que fracassa, o que erra.

Deste modo, esse tipo de avaliação serve apenas para reconhecer se o aluno domina ou não determinado conteúdo, mas não tem capacidade para indicar qual saber o aluno usou para responder a questão proposta, quais "os processos de aprendizagem desenvolvidos para adquirir o conhecimento demonstrado" (ESTEBAN, 2001, p. 100), nem muito menos o raciocínio que o conduziu a essa resposta.

Hoffmann (2003) desenvolve um estudo pertinente em relação à avaliação na educação infantil. Para a autora, a avaliação tem duplo objetivo, qual seja o de controlar a ação do professor e o comportamento do aluno. Essas avaliações são realizadas por meio de práticas avaliativas positivas, com reflexos de concepçôes elitistas e discriminatórias, descontextualizadas do cotidiano da criança, pois não levam em conta sua individualidade, nem a prática do professor. Esse modelo de avaliação, exercido há muitos anos no ensino 
fundamental, tem sido utilizado também na educação infantil, embora a proposta desta seja outra.

A proposta da educação infantil, de acordo com o Referencial Curricular Nacional para a Educação Infantil (BRASIL, 1998), é que as crianças devem ser compreendidas em seus contextos sociais, ambientais, culturais e em suas interações e práticas sociais. Além disso, é apresentado no texto o conceito de educar para a educação infantil, que significa propiciar situações de cuidados, brincadeiras e aprendizagens de forma integrada e que contribuam para o desenvolvimento de relaçóes interpessoais e conhecimentos da realidade social e cultural etc.

A avaliação, portanto, deve ter um caráter dialógico entre o professor e a criança, permeado por uma atmosfera em que a emocionalidade de ambos deve ser compreendida como espaço de desenvolvimento, por promover sentidos subjetivos a respeito das atividades e interações desenvolvidas e que promovem a necessidade da criança de novos aprendizados e novos sentidos subjetivos.

O professor, ao avaliar o aluno, deve visualizar o que a criança pode vir a saber, lembrando-se da zona de desenvolvimento proximal, que transforma o processo ensinoaprendizagem em um saber compartilhado, construído individualmente e no grupo, pois, por meio da mediação do grupo, a criança aprende e se desenvolve. Assim, " a zona de desenvolvimento proximal indica os pontos em que a aprendizagem necessita de apoio, não a impossibilidade de o sujeito aprender" (ESTEBAN, 2001, p. 149, grifo da autora). $\mathrm{O}$ professor deve trabalhar com as possibilidades que a criança tem para o aprender e isso ele só consegue perceber através de uma relação dialógica com a criança.

Quando a comunicação professor-aluno não acontece e, infelizmente, na maioria das instituições de ensino as avaliações são descontextualizadas do cotidiano da criança sem observar suas potencialidades, que são desenvolvidas na interação com o outro em um contexto emocional, a criança que não se desenvolve de acordo com as categorias utilizadas pelo professor é estigmatizada e excluída das atividades. Assim, passa a ser significada pelo professor como uma criança que não se desenvolve, seus movimentos para participar das atividades são desconsiderados, o professor passa a não percebê-la como sujeito, muitas vezes nem escuta o que a criança tem a dizer e só a percebe quando é para chamar-lhe a atenção e criticá-la. A criança percebe essas interações e, dependendo de outras situações nas quais se desenvolve, como na esfera familiar, ela passa a produzir um sentido subjetivo e se significar como uma criança fracassada, que não consegue deixar as pessoas felizes com suas ações. É importante lembrar que os sentidos subjetivos não acontecem apenas na esfera consciente do sujeito, mas a consciência-inconsciência são dois momentos da experiência subjetiva (GONZÁLEZ REY, 2003). Por isso, muitas vezes a criança não consegue se expressar sobre seus sentimentos de inferioridade, baixa auto-estima, dificuldade de relacionamento, mas que fazem parte de sua constituição subjetiva e que em outras situações futuras podem se configurar em dificuldades de aprendizagem. 


\section{CONSIDERAÇÕES FINAIS}

Baseados nessa discussão, na qual a interação e a mediação têm papel fundamental nas relações que se estabelecem na escola, entendemos o processo de inclusão/exclusão como dialético e, portanto, contraditório. Tal processo constitui as crianças em sua vida escolar, que se inicia muitas vezes na educação infantil - e na creche para as crianças das classes sociais menos favorecidas materialmente. Muitas crianças que são excluídas nesse processo são significadas como "deficientes" devido a seu desenvolvimento (e tudo o que ele engloba: linguagem, emoção, interação etc.) não estar de acordo com os padrões estabelecidos pelas pessoas que cuidam dos processos de ensino-aprendizagem, como na história Os Caminhos de Sofia na Creche (LIMA, 2004).

Além disso, acreditamos que as professoras, no seu compromisso com a educação e o desenvolvimento humano, devem trabalhar com a diversidade em sala de aula, não olhando apenas para o aluno modelo, mas para todas as crianças que estão envolvidas no processo educativo. O educador tem a obrigação de perceber o ser humano como complexo e singular, além de contextualizá-lo num espaço social e histórico e compreendê-lo como sujeito que, por meio da interação com o outro, desenvolve e constrói seu conhecimento.

A interação, a comunicação e a mediação educador-criança são aspectos fundamentais para o desenvolvimento e a inclusão escolar. É através da mediação de um outro mais apto que a criança começa a conhecer o mundo ao seu redor, a produzir significado e sentido subjetivo sobre suas ações e assim passa a se constituir como sujeito nas relações intersubjetivas que estabelece ao longo de sua vida.

Essas interações nos levam a compreender como se desenvolve o processo de inclusão/ exclusão da criança, pois cada interação é permeada pelos significados e sentidos que o educador produziu e produz sobre a criança e como a criança se posiciona e se sente na interação com o educador.

O processo de inclusão/exclusão se constitui, portanto, a partir das interações que se produzem nos espaços sociais. Nesse sentido, um aspecto relevante para ser discutido e priorizado, embora não pretendamos discutir neste espaço o assunto com a profundidade que merece, é a formação das pessoas que trabalham nas instituições de ensino, a começar pela pessoa que recebe as crianças na entrada da escola até o educador que vive o dia-a-dia com elas.

A formação de professores deve ser humana, no sentido em que devem compreender as crianças não como uma tábula rasa ou como indivíduos destruídos pelas suas condições socioeconômicas. Uma das grandes dívidas da psicologia para com o senso comum foi a "psicologização" da vida, na qual todas as dificuldades encontradas pelas crianças e suas famílias levam a traumas irreversíveis, que apenas por meio de um acompanhamento psicológico poderão ser resolvidos. Tal compreensão não leva em consideração a diversidade humana, na medida em que o sujeito produz sentido subjetivo muitas vezes diverso da dificuldade a que foi acometido. Essa relação de causa-efeito, instituída por uma psicologia racionalista-positivista, não percebe a complexidade humana, na qual o indivíduo, a partir de novas produções de sentido, é capaz de se desenvolver na adversidade. 
A compreensão de um desenvolvimento humano articulado a uma concepção de unidade psíquica afetivo-cognitiva pode auxiliar no trabalho em educação de crianças. O desenvolvimento do ser humano começa antes de seu nascimento, com as sensaçóes que o feto tem no útero materno, mas não pára aos três anos de idade, nem na adolescência, muito menos com a morte, pois a morte de alguém nos diz respeito e nos leva ao desenvolvimento. Além do que, viver e desenvolver-se é morrer a cada dia, e a lembrança da morte pode nos fazer viver mais intensamente. Vygotsky (1999, p. 266) discutiu a respeito da morte e a compreendeu como uma concepção dialética da vida:

A morte é interpretada somente como uma contraposição contraditória da vida, como a ausência de vida, em suma, como o não-ser. Mas a morte é um fato que tem também seu significado positivo, é um aspecto particular do ser e não só do não-ser; é um certo algo e não o completo nada. E esse significado positivo da morte é desconhecido da biologia. Na verdade, a morte é a lei universal do vivo; é impossível conceber que esse fenômeno nada represente no organismo, isto é, nos processos da vida. É difícil crer que a morte careça de significado ou só tenha um significado negativo.

Dessa forma, uma proposta de desenvolvimento que articule todos os processos humanos, complexos e contraditórios, pode auxiliar na formação dos educadores e em novas produções de sentidos e significados a respeito do que é humano, que não deve ser categorizado e padronizado em conceitos de anormalidades e deficiências, mas na compreensão de como acontece a constituição subjetiva das crianças.

A importância do educador em sua interação com a criança não é aqui maximizada como único fator de constituição da criança, nem tampouco menosprezada. A criança vive em outros espaços sociais, mas devemos pensar que é na escola que ela passa parte de seu tempo e aprende conteúdos formais. Por isso os serviços ali prestados devem ser de qualidade, com o objetivo de promoção de saúde das crianças e das pessoas que ali trabalham.

As propostas devem se constituir na busca de melhores condições de trabalho para os educadores, com cursos e formação acadêmica que lhes possibilitem se sentir como produtores de conhecimento e transformadores da realidade em que vivem, sendo assim sujeitos em sua vida e em sua profissão. E que tal formação se constitua em vínculos significativos com as crianças, para que estas, em espaços físicos adequados às suas necessidades físicas e emocionais, se desenvolvam brincando e aprendendo a viver com qualidade e dignidade. Lembrando sempre que, embora reconhecidas como seres humanos diferentes, pois todos somos diferentes a partir de nossas características subjetivas, as crianças devem ter reconhecidos seus direitos de igualdade de oportunidades de educação, saúde e acesso aos bens materiais. 


\section{Notas}

1. A Declaração de Cuenca (1981) pode ser encontrada em: CARVALHO, Rosita Edler. A nova $L D B$ e a educação especial. Rio de Janeiro: WVA, 1997.

2. A Declaração de Salamanca (1994) pode ser encontrada em: <http.//portal.mec.gov.br/seesp/ arquivos/pdf/salamanca/pdf>. Acesso em: 10 nov. 2006.

3. Tradução nossa. No original lê-se "handicapped condition is only a social concept; a defective condition is an abnormal extension of blindness, deafness, or muteness. Blindness by itself does not make a child handicapped' (VYGOTSKY, 1993, p. 83-84).

4. Ao nos referirmos sobre emocionalidade e afetividade nas relações intersubjetivas utilizamos como referencial teórico González Rey, 2003.

\section{Referências}

AGUIAR, Wanda Maria J. de; BOCK, Ana Mercês Bahia. Psicologia da educação: em busca de uma leitura crítica e de uma atuação compromissada. In: BOCK, Ana Mercês Bahia (Org.). A perspectiva sócio-histórica na formação em psicologia. Petrópolis: Vozes, 2003. p.132-160.

ANTUNES, Mitsuko Aparecida Makino. A psicologia no Brasil: leitura histórica sobre sua constituição. São Paulo: Unimarco e Educ, 1999.

BARBOZA, Sandra F. Incluindo a professora: subjetividade no contexto da inserção de crianças com necessidades educacionais especiais em classes comuns de ensino. 2001. Dissertação (Mestrado em Psicologia), Universidade Católica de Goiás. Goiânia, 2001.

BOCK, Ana Mercês Bahia. Psicologia e sua ideologia: 40 anos de compromisso com as elites. In: . (Org.). Psicologia e o compromisso social. São Paulo: Cortez, 2003. p. 15-28.

BRASIL, Ministério da Educação e do Desporto. Secretaria de Educação Fundamental. Referencial curricular nacional para a educação infantil, vol. 1. Brasília: MEC/SEF, 1998.

CUENCA, 1981. In: CARVALHO, Rosita Edler. A nova $L D B$ e a educação especial. Rio de Janeiro: WVA, 1997.

CUPOLILLO, Mercedes Villa. Aprendizagem e desenvolvimento em crianças com necessidades especiais. Jornal da APAE, Goiânia, GO, dez. 2003 (periodicidade bimestral), p. 2-3.

ESTEBAN, Maria Teresa. O que sabe quem erra? Reflexões sobre avaliação e fracasso escolar. Rio de Janeiro: DP\&A, 2001.

FERREIRA, Maria Elisa Caputo; GUIMARÃES, Marly. Educação inclusiva. Rio de Janeiro: DP\&A, 2003.

FUNDAÇÃO BANCO DO BRASIL. Midia e deficiência. Brasília: Andi; Fundação Banco do Brasil, 2003.

GONZÁLEZ REY, Fernando. Pesquisa qualitativa em psicologia: caminhos e desafios. São Paulo: Pioneira Thomson Learning, 2002.

. Sujeito e subjetividade: uma aproximação histórico-cultural. São Paulo: Pioneira Thomson Learning, 2003.

HOBSBAWM, Eric J. A era das revoluções: 1789-1848. Rio de Janeiro: Paz e Terra, 1982. . Era dos extremos: o breve século XX - 1914-1991. São Paulo: Companhia das Letras, 1995. 
HOFFMANN, Jussara. Avaliação na pré-escola: Um olhar sensível e reflexivo sobre a criança. Porto Alegre: Mediação, 2003.

LIMA, Candice Marques. O processo de inclusãolexclusão na constituição subjetiva de crianças na creche. 2004. Dissertação (Mestrado em Psicologia), Universidade Católica de Goiás. Goiânia, 2004. MANTOAN, Maria Teresa Eglér. Ser ou estar: eis a questão: explicando o déficit intelectual. Rio de Janeiro: WVA, 2000.

MORIN, Edgar. A cabeça bem feita. Rio de Janeiro: Bertrand Brasil, 2000.

PATTO, Maria Helena de Sousa. A produção do fracasso escolar: histórias de submissão e rebeldia. São Paulo: T.A.Queiroz, 1996.

. O que a história pode dizer sobre a profissão do psicólogo: a relação psicologia-educação.

In: BOCK, Ana Mercês Bahia (Org.). Psicologia e o compromisso social. São Paulo: Cortez, 2003. p. 29-35.

SALAMANCA, 1994. Disponível em: <http://portal.mec.gov.br/seesp/arquivos/pdf/salamanca/pdf>. Acesso em: 10 nov. 2006.

SOUSA, Ana Maria Costa. Educação infantil: uma proposta de gestão municipal. Campinas: Papirus, 2000.

VYGOTSKY, Lev Semenovich. The fundamentals of defectology: abnormal psycology and learning disabilities. New York: Plenum Press, 1993. Teoria e método em psicologia. São Paulo: Martins Fontes, 1999. 


\section{The historical cultural theory and dialectic inclusion/exclusion in education institutions}

Abstract

The present article intends to discuss the process of school inclusion/exclusion from the historical cultural perspective. In this perspective, we discuss inclusion as a dialectic process that happens to individuals involved in educational contexts by means of intersubjective relationships. As a complex and contradictory process, inclusion is not limited to the idea of deficiency. But it extends itself to all the members of the groups to which an individual belongs, promoting pedagogical and social practices which cater to human diversity. According to this proposal, dialogical communication between teacher and pupil is the main element so that these constitute themselves as subjects of their knowledge process, feeling themselves included in the social and human relationships.

Keywords: Historical cultural approach. Inclusion. Diversity. Communication.

\section{La théorie historico-culturelle et la dialectique inclusion/exclusion dans les institutions d'enseignement \\ Résumé}

Le présent article prétend discuter le processus de l'inclusionlexclusion scolaire à partir de l'approche historicoculturelle. Dans cette perspective, nous discutons l'inclusion comme un processus dialectique qui se produit dans les individus qui sont impliqués dans les contextes éducationnels, au travers de relations intersubjectives. Complexe et contradictoire, le processus d'inclusion n'est pas limité à la vision de déficience, mais sétend à tous les membres des groupes auxquels l'individu appartient, promouvant des pratiques pédagogiques et sociales pour répondre à la diversité humaine. Dans cette proposition, la communication dialogique entre mâ̂tre et élève est le point fondamental pour que celui-ci se constitue comme sujet de son processus d'apprentissage, se sentant inclus dans les relations sociales et humaines.

Mots clefs: Approche historico-culturelle. Inclusion. Diversité. Communication.

\section{La teoría histórico-cultural y la dialética inclusión/ exclusión en las instituciones de enseñanza \\ Resumen}

El presente artículo tiene como objetivo discutir el proceso de inclusión/ exclusión escolar a partir de la perspectiva histórico-cultural. En esa perspectiva discutimos la inclusión como un proceso dialético que ocurre en los individuos envueltos en los contextos educacionales, por medio de relaciones intersubjetivas. Complejo y contradictorio, el proceso de inclusión no está limitado a la visión de la deficiencia, pero se extiende a todos los miembros de grupos a que el individuo pertenece, promoviendo prácticas pedagógicas y sociales para atender a la diversidad humana. En esa propuesta, la comunicación dialógica entre profesor y alumno es el punto fundamental para que este se constituya como sujeto en su proceso de conocimiento, sintiéndose incluido en las relaciones sociales y humanas.

Palabras-clave: Teoría histórico-cultural. Inclusión. Diversidad. Comunicación. 